\title{
Incorporating Theory into Practice: Reconceptualizing Exemplary Care Coordination Initiatives from the US Veterans Health Delivery System
}

\author{
Kathryn M. McDonald, MM, $P h D^{7}$, Sara J. Singer, MBA, $P h D^{1,2}$, Sherri Sheinfeld Gorin, PhD ${ }^{3,4}$, \\ David A. Haggstrom, MD, MAS ${ }^{5,6}$, Denise M. Hynes, MPH, PhD, RN 7,8 , Martin P. Charns, DBA 9,10 , \\ Elizabeth M. Yano, PhD, MSPH ${ }^{17,12}$, Michelle A. Lucatorto, DNP, FNP-C ${ }^{13}$, \\ Donna M. Zulman, MD, MS ${ }^{1,14}$, Michael K. Ong, MD, PhD 17,12,15, R. Neal Axon, MD, MSCR ${ }^{16,17}$, \\ Donna Vogel, $\mathrm{MSN}^{13}$, and Mark Upton, $\mathrm{MD}^{18}$
}

\begin{abstract}
'Center for Health Policy/Center for Primany Care and Outcomes Research, Stanford University School of Medicine, Stanford University, Stanford, CA, USA; ${ }^{2}$ Stanford University Graduate School of Business, Stanford, CA, USA; ${ }^{3}$ New York Physicians against Cancer (NYPAC), New York, NY, USA; ${ }^{4}$ The University of Michigan Medical School, Ann Arbor, MI, USA; ${ }^{5}$ Indianapolis VA Medical Center, Indianapolis, IN, USA; ${ }^{6}$ Indiana University School of Medicine, Indianapolis, IN, USA; ${ }^{7}$ Center to Improve Veteran Involvement in Care (CIVIC), VA Portland Health Care System, Portland, OR, USA; ${ }^{8}$ College of Public Health and Human Sciences, Oregon State University, Corvallis, OR, USA; ${ }^{V}$ VA HSR\&D Center for Healthcare Organization and Implementation Research (CHOIR), VA Boston Healthcare System, Boston, MA, USA; ${ }^{10}$ Boston University School of Public Health, Boston, MA, USA; "VA HSR\&D Center for the Study of Healthcare Innovation, Implementation \& Policy, VA Greater Los Angeles Healthcare System, Los Angeles, CA, USA; ${ }^{12}$ Department of Health Policy \& Management, UCLA Fielding School of Public Health, Los Angeles, CA, USA; ${ }^{13}$ VA Office of Nursing Services, Washington, DC, USA; ${ }^{14}$ VA Palo Alto, Palo Alto, CA, USA; ${ }^{15}$ Department of Medicine, David Geffen School of Medicine at UCLA, Los Angeles, CA, USA; ${ }^{16}$ Ralph H. Johnson Veterans Affairs Medical Center, Charleston, SC, USA; ${ }^{17}$ Medical University of South Carolina, Charleston, SC, USA; ${ }^{18}$ VHA Office of Community Care, Denver, CO, USA.
\end{abstract}

This perspective paper seeks to lay out an efficient approach for health care providers, researchers, and other stakeholders involved in interventions aimed at improving care coordination to partner in locating and using applicable care coordination theory. The objective is to learn from relevant theory-based literature about fit between intervention options and coordination needs, thereby bringing insights from theory to enhance intervention design, implementation, and troubleshooting. To take this idea from an abstract notion to tangible application, our workgroup on models and measures from the Veterans Health Administration (VA) State of the Art (SOTA) conference on care coordination first summarizes our distillation of care coordination theoretical frameworks (models) into three common conceptual domains - context of an intervention, locus in which an intervention is applied, and specific design features of the intervention. Then we apply these three conceptual domains to four cases of care coordination interventions ("use cases") chosen to represent various scopes and stages of interventions to improve care coordination for veterans. Taken together, these examples make theory more accessible and practical by demonstrating how it can be applied to specific cases. Drawing from theory offers one method to anticipate which intervention options match a particular coordination situation.

KEY WORDS: care coordination; integrated care; theoretical model; theoretical framework.

J Gen Intern Med 34(Suppl 1):S24-S9

DOI: $10.1007 / \mathrm{s} 11606-019-04969-\mathrm{w}$

(c) Society of General Internal Medicine (This is a U.S. government work and not under copyright protection in the U.S.; foreign copyright protection may apply) 2019

Published online May 16, 2019

\section{PERSPECTIVE NARRATIVE}

Improving care coordination is a top priority for the Veterans Health Administration (VA), the largest U.S. integrated health care system. Poor care coordination is associated with lower care quality, inadequate symptom control, and higher rates of medical errors and costs. ${ }^{1}$

Theoretical frameworks are fundamental to making systematic delivery system improvements in care coordination. They provide guidance in the design of care coordination initiatives as well as measures for assessing changes resulting from interventions. Many frameworks exist to guide practitioners in improving and evaluating the robustness of care coordination; however, application of these frameworks by delivery system managers seems limited, potentially due to insufficient opportunities to bridge the gap between theory and practice. In response, the VA State of the Art (SOTA) conference on Care Coordination brought together researchers and operational managers to assess the evidence for translating theory into practice.

Our SOTA Workgroup focused on theoretical frameworks and measures of coordination. Planning efforts were informed by a concurrent systematic rapid review (of theoretical frameworks) conducted by the VA Evidence-Based Synthesis Program (ESP), accompanied by 6 months of expert consensusbuilding. $^{2}$ The workgroup process involved 1.5 days of inperson structured deliberation. In order to make findings more actionable, our workgroup decided to apply the theoretical frameworks to four major VA-based interventions ("use cases") selected to represent various scopes and different stages of development, ranging from piloting to implementation. 
We aim to make the theoretical frameworks identified through the SOTA a more practical resource for operational managers and researchers focused on care coordination. The use cases allow us to show how the theories discussed during the SOTA conference apply to real-life examples.

\section{The Four Use Cases}

A subset of the SOTA Workgroup familiar with the selected VA use cases (DZ, ML, DV, NA, MO) answered prompts created by the workgroup leaders to provide structured information. First, we wanted a description that established the intervention name, what motivated the need for an intervention, who and what the intervention aimed to coordinate, the stage of implementation in the VA system, specific implementation sites, evaluations conducted or planned, and results from the evaluations. Table 1 briefly summarizes this information for each of the four use cases-PIM: Patient Aligned Care Team (PACT) Intensive Management, which focuses on coordination within the primary care setting; CC-ICM: Care Coordination and Integrated Case Management, which focuses on coordination for complex patients without regard to setting; I-STEP: Improving Transplant Medication Safety through Technology and Pharmacist (original and expanded), which focuses on one aspect of coordination-medication management; and $\mathrm{H} 2 \mathrm{C}$ : Hospital 2 Community, which focuses on transitions between care systems.

We also asked our use case informants about what prior models-similar interventions and conceptual underpinnings - were used to inform intervention choices. PIM drew lessons from the Coleman et al. care transition model, the Camden hotspotter model, and the GRACE model for older adults. ${ }^{3}$ The CC-ICM started with a set of general principles and a toolkit from the Case Management Society of America. ${ }^{4}$ The third use case represents phased intervention design from the original I-STEP model $^{5}$ to an expanded model for a broader patient population at risk of medication safety events. $\mathrm{H} 2 \mathrm{C}$ is based on theory that highlights interactions between organizations and their environments, and the Community Partners in Care Model. ${ }^{6}$

To make the linkage between theory and practice accessible to a wide audience, we organized information about each use case into three SOTA-created conceptual domains - the context surrounding an intervention, an intervention's locus (setting, level, and purpose), and elements of its design (mechanisms and types of interventions), as described in an ESP companion article. ${ }^{2}$ This exercise demonstrates linkages to a growing body of theory work that posits, often with empirical support, what interventions will work under what conditions. This body of theoretical work also underpins measurement development and testing, which is important for evaluating processes, intermediate outcomes, and patient experiences of care coordination interventions.

Table 2 provides an example of this domain mapping for the four use cases, and the following sections demonstrate our suggested domain-based approach to drawing useful insights from the theory (identified in the ESP review ${ }^{2}$ ) for these use cases. For each domain, we briefly describe what it is, note the number of theories from the ESP review that speak to the specific domain, and finally show applicability of the domain to one or more use cases through selected examples from the subset of theories available.

Drawing from Theory to Inform and Interpret Use Cases: Context Domain. The context for an intervention refers to external factors that enable or thwart an intervention's success at any stage of implementation. ${ }^{7,8}$ At the stage of intervention design, some contextual factors may be completely impossible to change (e.g., for the PIM case, the electronic medical record system), while others, if modified, become part of the intervention instead of the context. For example, to expand I-STEP from transplant patients to other patients, the intervention team is collecting data to understand the broader context and what can be changed to avoid coordination failures that lead to medication safety events.

Based on the ESP review, 15 theoretical frameworks suggest questions to pose to understand the context for coordination. For the H2C, for example, Van Houdt's framework suggests asking what are the interdependencies between policy for Veterans to access different providers (within and outside of the VA) and the current structures of care delivery (teams, organizations, and inter-organizational networks)? ${ }^{9}$ In turn, the theory suggests investigating factors that influence structures, such as, what information is required to manage the care of the $\mathrm{H} 2 \mathrm{C}$ target population individually and as a group. ${ }^{9}$

The Calciolari et al. theoretical framework assesses antecedents to aligning "healthcare provision with evolving patient needs" both in the context of a single organization, such as the VA, and for coordinated "service delivery across health and social care providers." 10 For both the H2C and CC-ICM use cases, this framework points to "incentives and impediments" that influence attempts to integrate care at the organizational level: "institutional adequacy" which relates to people who can manage knowledge complexity (e.g., the different staffing models noted for $\mathrm{CC}-\mathrm{ICM}$ ), and resource commitment to integration (e.g., what resource commitments are available for a sustainable CC-ICM model), and "focus on results" (e.g., metrics and feedback, which may enable or present challenges for each use case situation). ${ }^{10,11}$

Drawing from Theory to Inform and Interpret Use Cases: Locus Domain. Determinations regarding locus include deciding where the intervention is aiming to have an impact (i.e., setting including who is involved in caring for what specific patient populations, and scope in terms of levels from individuals [micro] to clinic teams [meso] to physician organizations or broader health systems [macro]) and what the intervention is trying to achieve (i.e., purpose[s]). For example, the locus of the CC-ICM intervention includes its setting which is system-wide; multiple levels including case managers or care managers (depending on patient need) who act as individuals or in teams; and purpose, which is to coordinate with both medical and social service providers 
Table 1 Description of Four Use Cases

\begin{tabular}{|c|c|c|c|c|}
\hline \multirow{2}{*}{$\begin{array}{l}\text { Intervention } \\
\text { details }\end{array}$} & \multirow{2}{*}{$\begin{array}{l}\text { Use case \#1 } \\
\text { PIM: Patient Aligned Care Team } \\
\text { (PACT) Intensive Management }\end{array}$} & \multirow{2}{*}{$\begin{array}{l}\text { Use case \#2 } \\
\text { CC-ICM: Care } \\
\text { Coordination and } \\
\text { Integrated Case } \\
\text { Management }\end{array}$} & \multirow{2}{*}{$\begin{array}{l}\text { Use case \#3 } \\
\text { I-STEP: Improving } \\
\text { Transplant Medication Safety } \\
\text { through Technology and } \\
\text { Pharmacist (original and } \\
\text { expanded) }\end{array}$} & \multirow{2}{*}{$\begin{array}{l}\text { Use case \#4 } \\
\text { H2C: Hospital } 2 \\
\text { Community }\end{array}$} \\
\hline & & & & \\
\hline $\begin{array}{l}\text { Coordination } \\
\text { aim }\end{array}$ & $\begin{array}{l}\text { - Care coordination for veteran } \\
\text { primary care patients at high risk for } \\
\text { hospitalization and with a recent } \\
\text { acute care episode }\end{array}$ & $\begin{array}{l}\text { - Care coordination for } \\
\text { veterans with significant } \\
\text { biopsychosocial needs, } \\
\text { high service utilization, } \\
\text { and/or at risk for high } \\
\text { service utilization or poor } \\
\text { outcomes }\end{array}$ & $\begin{array}{l}\text { - Coordination of medications } \\
\text { for veterans receiving care in } \\
\text { the community, expanding } \\
\text { from original } \\
\text { population-patients who have } \\
\text { had a transplant }\end{array}$ & $\begin{array}{l}\text { - Care coordination } \\
\text { between the VA health } \\
\text { care system, community- } \\
\text { based organizations, and } \\
\text { the patient }\end{array}$ \\
\hline $\begin{array}{l}\text { Motivation for } \\
\text { intervention }\end{array}$ & $\begin{array}{l}\text { - Leadership priorities from VA } \\
\text { Office of Primary Care }\end{array}$ & $\begin{array}{l}\text { - Findings from VA } \\
\text { Commission on Care } \\
\text { Report (2016) } \\
\text { - Leadership priorities } \\
\text { from VA Nursing and } \\
\text { Social Work }\end{array}$ & $\begin{array}{l}\text { - Original: observed } \\
\text { medication safety issues } \\
\text { - Expanded: concern for } \\
\text { medication safety in care } \\
\text { transitions for all veterans led } \\
\text { to VA National Center for } \\
\text { Patient Safety (NCPS) project }\end{array}$ & $\begin{array}{l}\text { - Priority and project } \\
\text { comes from VA QUERI } \\
\text { (Quality Enhancement } \\
\text { Research Initiative) Care } \\
\text { Coordination Program }\end{array}$ \\
\hline $\begin{array}{l}\text { Stage of } \\
\text { development }\end{array}$ & $\begin{array}{l}\text { - Implementation evaluated } \\
\text { - Sites are still adapting the } \\
\text { intervention, via interorganization } \\
\text { collaborative }\end{array}$ & $\begin{array}{l}\text { - Early implementation of } \\
\text { the core activities } \\
\text {-Innovation encouraged } \\
\text { outside core activities }\end{array}$ & $\begin{array}{l}\text { - Original: early } \\
\text { Implementation } \\
\text { - Expanded: planning stage }\end{array}$ & - Planning stage \\
\hline $\begin{array}{l}\text { Intervention } \\
\text { description }\end{array}$ & $\begin{array}{l}\text { - Interdisciplinary PIM teams assess } \\
\text { patient goals and offer services (e.g., } \\
\text { medication reconciliation, } \\
\text { home visits) } \\
\text { - Teams coordinate all aspects of } \\
\text { care, including medical and } \\
\text { social services } \\
\text { - Coordination activities such as } \\
\text { following up after emergency } \\
\text { department/hospitalization, electronic } \\
\text { consults with VA specialists, } \\
\text { updating VA records with } \\
\text { information about non-VA } \\
\text { medications/test results, sending VA } \\
\text { records to non-VA providers }\end{array}$ & $\begin{array}{l}\text { - Intensive case } \\
\text { management targeting the } \\
\text { veterans at highest need/ } \\
\text { risk (top 15-20\%) } \\
\text { - Care management for the } \\
\text { next highest need/risk } \\
\text { - Case management } \\
\text { component includes } \\
\text { baseline assessment for } \\
\text { improvement, designation } \\
\text { of champions at each } \\
\text { facility, creation of clinical } \\
\text { review team with specific } \\
\text { tasks, and validation of } \\
\text { supporting tools } \\
\text { - Care management } \\
\text { component includes } \\
\text { anticipatory disease } \\
\text { management, health } \\
\text { promotion, and support for } \\
\text { self-care and care givers }\end{array}$ & $\begin{array}{l}\text { - Clinical dashboard, updated } \\
\text { daily, to identify patients at risk } \\
\text { for medication problems } \\
\text { - Close contact with regional } \\
\text { transplant centers and } \\
\text { community hospitals allows } \\
\text { notification of acute health } \\
\text { care events } \\
\text { - Pre-specified algorithms and } \\
\text { medication reconciliation used } \\
\text { by pharmacists to ensure accu- } \\
\text { rate and safe medication regi- } \\
\text { mens } \\
\text { - Facilitated follow-up appoint- } \\
\text { ments and laboratory testing } \\
\text { - VA pharmacist coordinates } \\
\text { medications to avoid formulary } \\
\text { mismatches, ensures timely } \\
\text { prescription fills, and avoids } \\
\text { medication-related adverse } \\
\text { events }\end{array}$ & $\begin{array}{l}\text { - Interventions will } \\
\text { address four key } \\
\text { challenges: } \\
\text { - Patient biopsychosocial } \\
\text { needs for services after } \\
\text { inpatient care } \\
\text { - Hospitals provide } \\
\text { limited coordination } \\
\text { following discharge } \\
\text { - Health care systems } \\
\text { have few resources to } \\
\text { provide social services } \\
\text { - VA social service } \\
\text { resources are not } \\
\text { necessarily coordinated } \\
\text { with communities where } \\
\text { patients reside }\end{array}$ \\
\hline Scope & $\begin{array}{l}\text { - Five VA facilities in GA, OH, WI, } \\
\text { NC, and CA since } 2014\end{array}$ & $\begin{array}{l}\text { - } 12 \text { sites across country, } \\
\text { starting in } 2017 \text {, with plans } \\
\text { to expand to additional } \\
\text { sites as part of a second } \\
\text { phase }\end{array}$ & $\begin{array}{l}\text { - Original: currently being } \\
\text { implemented in } 10 \text { VA Medical } \\
\text { Centers across the country } \\
\text { since } 2017 \\
\text { - Expanded: will start at one } \\
\text { VA Medical Center in } 2019\end{array}$ & $\begin{array}{l}\text { - Expected to be } \\
\text { implemented in several } \\
\text { Service Planning Areas } \\
\text { (in Los Angeles County } \\
\text { in 2018), with plans to } \\
\text { expand to other sites }\end{array}$ \\
\hline Results & $\begin{array}{l}\text { - Evaluated in a randomized trial } \\
\text { during the first } 12 \text { months } \\
\text { - PIM } \uparrow \text { primary care and social work } \\
\text { services and outpatient costs } \\
-\downarrow \text { Inpatient costs resulting in similar } \\
\text { total costs* } \\
\text { - Modest } \uparrow \text { patient experience of care }\end{array}$ & $\begin{array}{l}\text { - Evaluation underway is } \\
\text { focused on understanding } \\
\text { the implementation } \\
\text { process } \\
\text { - Future evaluations will } \\
\text { focus on program } \\
\text { outcomes (readmission, } \\
\text { ER visits, ambulatory care } \\
\text { sensitive admissions) }\end{array}$ & $\begin{array}{l}\text { - Original: substantially } \uparrow \text { rates } \\
\text { of appropriate } \\
\text { immunosuppressant drug } \\
\text { monitoring for transplant } \\
\text { patients }{ }^{\dagger} \\
\text { - Expanded: none yet }\end{array}$ & - None yet \\
\hline
\end{tabular}

*Yoon et al., Annals of Internal Medicine 2018; ${ }^{\dagger}$ Thrall SA et al., Progress in Transplantation 2017

and with veterans and their families. The ESP review links 28 care coordination theory articles to the locus domain.

Many of these theories offer opportunities to understand how locus drives the particular design of an intervention. For example, Gittell et al. describe how coordination communication networks can be evaluated at different levels (i.e., PIM: the meso level of activities within a team focused on primary care patients, while the others include macrolevel activities among organizations). ${ }^{12,13}$ The Gittell et al. relational coordination theory posits that many of the same considerations for coordination operate at the different levels and in different settings, likely because of the common purpose of coordinating interdependent activity. ${ }^{12}$ Benzer et al. highlight some of the coordination challenges (and solutions) related to primary care and mental health clinical integration, a purpose that our PIM informants noted became more apparent after the intervention started enrolling patients (as a high proportion needed mental health care services). ${ }^{14}$ 
Table 2 Description of Use Cases Based on SOTA-Created Domains from Care Coordination Theoretical Frameworks Review

\begin{tabular}{|c|c|c|c|c|}
\hline \multirow{2}{*}{$\begin{array}{l}\text { Domains for } \\
\text { theory linkage }\end{array}$} & Use case \#1 & Use case \#2 & Use case \#3 & Use case \#4 \\
\hline & $\begin{array}{l}\text { PIM: Patient Aligned Care } \\
\text { Team (PACT) Intensive } \\
\text { Management }\end{array}$ & $\begin{array}{l}\text { CC-ICM: Care } \\
\text { Coordination and } \\
\text { Integrated Case } \\
\text { Management }\end{array}$ & $\begin{array}{l}\text { I-STEP: Improving } \\
\text { Transplant Medication } \\
\text { Safety through Technology } \\
\text { and Pharmacist (expanded, } \\
\text { planning stage) }\end{array}$ & $\begin{array}{l}\text { H2C: Hospital } 2 \\
\text { Community }\end{array}$ \\
\hline
\end{tabular}

Context (i.e., assessments to identify and examples of)
- Different staffing models and requirements at each site are not changed by CCICM initiative, but expected to influence it - Conducted local needs assessments of VA PACT teams already assisting highrisk patients to assess context

- Non-VA more fixed, given structural (e.g., medical home) and functional (e.g., electronic medical record) differences
- Focus groups and chart reviews will be conducted to identify relevant contextual factors using the Consolidated Framework for Implementation Research categories (e.g., inner setting, outer setting) (Damscholder et al. 2009)
- Intervention planning will consider an open systems model (meaning organizations are influenced by resources and demands from external environment)

- Particular attention to interactions and communications between health care system and

- VA health care system, community clinics and settings outside VA, and patients non-clinical veteran-focused care activities and services

Purpose of intervention

- $\downarrow$ ED and hospital use - $\uparrow$ patient satisfaction - $\downarrow$ primary care provider burnout

- Generate a positive return on investment
- VA pharmacy in coordination with primary care and community partners

Multilevel

- Micro (interpersonal-level, intervention between veteran and pharmacist)

- Meso (team-level, including pharmacist and primary care

clinics)

- Macro (system-level intervention across health systems involved in care coordination)

- $\uparrow$ medication safety for patients receiving VAsponsored care in the community surrounding community
Multilevel

- Micro (interpersonal-level intervention for veteran and coordinator)

- Meso (team-level intervention with Case Management Review Teams)

- Macro (system-level intervention focused on care coordination)

Multilevel

- Micro (interpersonal-level, intervention between veteran and peer specialist [boundary spanner]*

- Meso (team level between peer specialists and primary care)

- Macro (system-level intervention across VA health system and community)

- $\uparrow$ communication across settings

- $\uparrow$ conduits to resources for patients discharged from the hospital who have

biopsychosocial needs (e.g., homelessness)

- $\downarrow$ readmissions

- $\downarrow$ extended lengths of stay

- Identify highest risk patients

- Assign them to a case manager and team

- Address biopsychosocial goals

- Provide intensive and personalized assessment, advocacy, implementation, coordination, and monitoring sition between care settings)

- Coordination of community
- Identify patients at high risk for medication-related adverse events (e.g., patients in tran-

- Conduct medication reconciliation - Overcome system-related barriers to safety, timely prescribing (e.g., formulary mismatches, medication duplications, delays in prescription fills)

- Activities to ensure appropriate follow up and laboratory monitoring

- Encompasses structural (clinical dashboard), functional (algorithms), and clinical coordination (i.e., medication reconciliation, facilitated follow-up appointments, and lab tests) resources that can benefit a discharged veteran through asset mapping and proactive meetings to encourage goal alignment around discharged veteran needs

- Access to community resources through peer specialists (more flexibility and higher trust among - Peer specialist supported by a social worker and other health care providers

- Linkage with a patient's PACT (akin to medical home) - Focuses on structural coordination (coordination boundary spanners, PACT link) veterans than a social worker) meetings, peers specialists as processes (e.g., medication management) structural, functione process integration (as defined by Singer 2018)

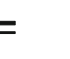


Theories also help identify important sets of questions related to locus for emerging interventions, such as the $\mathrm{H} 2 \mathrm{C}$ with its broad locus of coordinating care across organizations within and outside the VA. For example, the SELFIE model includes a category "information and research," which elicits questions about what is known about individual risk prediction of social resource needs (microlevel), opportunities for risk stratification (mesolevel), and barriers to information access (macrolevel) $?^{15}$ If the purpose is to improve patient safety through better coordination, as in the case of I-STEP, the Hodgson et al. model raises questions about the patient's need for interdisciplinary care, as a concept separate from the patient's susceptibility to a medical mistake. ${ }^{16}$

\section{Drawing from Theory to Inform and Interpret Use Cases:} Design Domain. Design refers to how gains in coordination are anticipated or achieved. Choices for designing interventions can be approached conceptually in two complementary ways, as mechanisms for coordinating and as types of coordination. Mechanisms are action-oriented descriptions of expected cause and effect. Types of coordination differentiate aspects such as organizational and social integrations (more granularly, structural, functional, normative, interpersonal, and clinical integrations $)^{17}$, or structures, processes, and outcomes of coordination. ${ }^{18}$ Another key concept is that there is not one ideal design, but rather the need to achieve a good fit between what requires coordinating and the menu of intervention options for the mechanisms and types to accomplish the results desired. ${ }^{17,} 19$ The four use cases demonstrate the range of mechanisms and types applied to the coordination challenges (Table 2).

Intervention leaders for the CC-ICM use case participated in the SOTA and have turned to several theoretical frameworks to further inform and refine their design choices. They are leveraging the Weaver et al. concept of multisystem teams to create a team of teams (e.g., the homelessness team, the primary care team, and the cardiology team) for their target populations, and plan to incorporate some of the coordinating mechanisms highlighted such as flow diagrams and tables of role responsibilities. ${ }^{20}$

For cases like PIM that depends on coordination within interdisciplinary teams as well as coordination among teams (e.g., primary care, VA specialists, and non-VA specialists), theories of team functioning (e.g., Lemieux-Charles et al. ${ }^{21}$ ), relational coordination (Gittell ${ }^{13}$ ), and programming and feedback (Young et al. ${ }^{22,}{ }^{23}$ ) can be applied to ensure effective team functioning and coordination. Young et al. and Gittell et al. both demonstrate that both programming and feedback mechanisms of coordination are positively related to patient outcomes. Applying this finding to PIM's coordination between primary care teams and other specialists would suggest identifying what activities can be specified in protocols, reminders, and checklists (forms of programming), and what relies on other mechanisms (such as team meetings, huddles) and processes for communication and joint problem solving (feedback). ${ }^{13,22,23}$ Additional guidance from Gittell would focus on interpersonal types of interventions that facilitate the development of common understanding and effective communication both within the PIM teams and between the PIM teams and other providers. ${ }^{13}$

\section{CONCLUSION}

As demonstrated by the structured tables for each use case prepared in partnership between researchers and practitioners from our SOTA Workgroup, it is feasible to set the stage for feedback loops between conceptually grounded research and practical needs of those developing and implementing interventions. Use cases have conceptual linkages that either explicitly or implicitly inform interventions, care coordination in practice, and evaluation and measurement planning. Throughout these steps, bridging theory and three conceptual domains (context, locus, and design) within the four use cases demonstrate the critical role of research and operational partnerships evident in the SOTA process. Others could take a similar approach of partnering to map their situation to the SOTAcreated theory domains, and then turn to the ESP review (and other literature searches as needed) to identify applicable theories for enhancing the design and evaluation of coordination improvement interventions. To the extent that health care providers apply care coordination theory to inform and communicate findings from intervention efforts, such as the use cases described, both practice and theory-based work can advance in tandem to achieve the promise of better coordinated care.

\begin{abstract}
Acknowledgements: We would like to thank the organizers of the SOTA Care Coordination Conference, in particular David Atkins and Geraldine McGlynn, as well as the entire Models and Measures Workgroup_Facilitators: Kathryn McDonald, MM, PhD; Sara Singer, MBA, PhD; Other Workgroup Members not part of the writing team: Kristin Cunningham, DBA; Joe Francis, MD, MPH; Mark Friedberg, MD; Linda Lipson; Kari, Nelson, MD, MSHS; and Sarah Scholle, DrPH. Dr. Yano's time was supported by a VA HSR\&D Senior Research Career Scientist Award (RCS 05-195), and VA HSR\&D supported the SOTA on Care Coordination.
\end{abstract}

Corresponding Author: Kathryn M. McDonald, MM, PhD; Center for Health Policy/Center for Primary Care and Outcomes Research, Stanford University School of Medicine, Stanford University, Stanford, CA, USA (e-mail: Kathryn.McDonald@stanford.edu).

\section{Compliance with Ethical Standards:}

Statement: The views expressed in this article are those of the authors and do not necessarily reflect the position or policy of the Department of Veterans Affairs or the United States government.

Conflict of Interest: The authors declare that they do not have a conflict of interest.

\section{REFERENCES}

1. Institute of Medicine (U.S.). Committee on Quality of Health Care in America. Crossing the quality chasm: a new health system for the 21 st century. Washington, D.C: National Academy Press; 2001.

2. Peterson K, Anderson J, Bourne D, Charns MP, Gorin SS, Hynes DM, et al. Health care coordination theoretical frameworks: a systematic 
review to increase their understanding and use in practice. JGIM J Gen Intern Med

3. Chang ET, Zulman DM, Asch SM, Stockdale SE, Yoon J, Ong MK, et al. An operations-partnered evaluation of care redesign for high-risk patients in the Veterans Health Administration (VHA): study protocol for the PACT Intensive Management (PIM) randomized quality improvement evaluation. Contemp Clin Trials. 2018;69(February):65-75.

4. Fraser K, Perez R, Latour C, (eds). CMSA's integrated case management a manual for case managers by case managers. 2018. $314 \mathrm{p}$.

5. Thrall SA, Egede LE, Taber DJ. Ambulatory care coordination issues with dual use veteran organ transplant recipients. Prog Transplant. 2017;27(2): 187-91.

6. Wells KB, Jones $\mathbf{L}$, Chung B, et al. Community-partnered clusterrandomized comparative effectiveness trial of community engagement and planning or resources for services to address depression disparities. JGIM J Gen Intern Med. 2013;28(10): 1268-78.

7. Damschroder LJ, Aron DC, Keith RE, Kirsh SR, Alexander JA Lowery JC. Fostering implementation of health services research findings into practice: a consolidated framework for advancing implementation science. Implement Sci. 2009;4(1):50.

8. McDonald KM. Considering context in quality improvement interventions and implementation: concepts, frameworks, and application. Acad Pediatr. 2013;13(6 SUPPL.):S45-53.

9. Van Houdt S, Heyrman J, Vanhaecht $\mathbf{K}$, Sermeus W, De Lepeleire J. An in-depth analysis of theoretical frameworks for the study of care coordination. Int J Integr Care. 2013;13:e024-e024.

10. Calciolari S, ninca S. Comparing (and learning from) integrated care initiatives: an analytical framework. J Integr Care. 2011;19(6):4-13.

11. Minkman M. The development model for integrated care: a validated tool for evaluation and development. J Integr Care. 2016;24(1):38-52.

12. Gittell JH, Weiss L. Coordination networks within and across organizations: a multi-level Framework. J Manag Stud. 2004;41(1):127-53.

13. Gittell JH. Coordinating mechanisms in care provider groups: relational coordination as a mediator and input uncertainty as a moderator of performance effects. Manage Sci. 2002;48(11):1408-26.
14. Benzer JK, Cramer IE, Burgess JF, Mohr DC, Sullivan JL, Charns MP. How personal and standardized coordination impact implementation of integrated care. BMC Heal Serv Res. 2015;15(1).

15. Leijten FRM, Struckmann V, van Ginneken E, Czypionka T, Kraus M, Reiss M, et al. The SELFIE framework for integrated care for multimorbidity: development and description. Health Policy (New York). 2017/07/03. 2018;122(1):12-22.

16. Hodgson A, Etzkorn L, Everhart A, Nooney $\mathbf{N}$, Bestrashniy $\mathbf{J}$. Exploring the validity of developing an interdisciplinarity score of a patient's needs: care coordination, patient complexity, and patient safety indicators. J Healthc Qual. 2017;39(2):107-21.

17. Singer SJ, Kerrissey M, Friedberg M, Phillips R. A comprehensive theory of integration. Med Care Res Rev. 2018/04/03. 2018;1077558718767000.

18. Donabedian A. Evaluating the quality of medical care. Milbank $Q$ 1966;44(No. 3, Pt. 2):166-203.

19. McDonald KM, Schultz E, Albin L, Lonhart J, Sundaram V, SmithSpangler C, et al. Care coordination measures atlas. 2014

20. Weaver SJ, Che $\mathbf{X X}$, Petersen LA, Hysong SJ. Unpacking care coordination through a multiteam system lens: a conceptual framework and systematic review. Med Care. 2018/01/23. 2018;56(3):247-59.

21. Lemieux-Charles L, McGuire WL. What do we know about health care team effectiveness? A review of the literature. Med Care Res Rev. 2006/05/03. 2006;63(3):263-300.

22. Young GJ, Charns MP, Daley J, Forbes MG, Henderson W, Khuri SF. Best practices for managing surgical services: the role of coordination. Health Care Manage Rev. 1997/11/14. 1997;22(4):72-81.

23. Young GJ, Charns MP, Desai K, Khuri SF, Forbes MG, Henderson W, et al. Patterns of coordination and clinical outcomes: a study of surgical services. Health Serv Res 1998/12/29. 1998;33(5 Pt 1):1211-36.

Publisher's Note Springer Nature remains neutral with regard to jurisdictional claims in published maps and institutional affiliations. 